Process Biochemistry,48(7): 1039-1047 (2013)

http://dx.doi.org/10.1016/j.procbio.2013.05.002

\title{
Hydrophobic adsorption and covalent immobilization of Candida antarctica lipase B on mixed-function-grafted silica gel supports for continuous-flow biotransformations
}

\author{
Zoltán Boros ${ }^{\mathrm{a}, \mathrm{b}}$, Diána Weiser ${ }^{\mathrm{a}}$, Mária Márkus a , Emese Abaháziováa ${ }^{\mathrm{a}}$, Ágnes Magyar ${ }^{\mathrm{a}}$, Anna \\ Tomin $^{\mathrm{a}}$, Béla Koczkac ${ }^{\mathrm{c}}$, Péter Kovács ${ }^{\mathrm{d}}$, László Poppe ${ }^{\mathrm{a}, \mathrm{b}}$, \\ - $\quad{ }^{a}$ Department of Organic Chemistry and Technology, Budapest University of Technology and \\ Economics, Müegyetem rkp. 3-9, H-1111 Budapest, Hungary \\ - $\quad{ }^{\mathrm{b}}$ SynBiocat Ltd., Lázár deák u. 4/1, H-1173 Budapest, Hungary \\ - $\quad{ }^{\mathrm{c}}$ Department of Inorganic and Analytical Chemistry, Budapest University of Technology and \\ Economics, Szent Gellért tér 4, H-1111 Budapest, Hungary \\ - ${ }^{\mathrm{d}}$ Department of Synthetic Organic Chemistry, Institute of Biomolecular Chemistry, Chemical Research \\ Center of the Hungarian Academy of Sciences, Pusztaszeri út 59-67, H-1025 Budapest, Hungary
}

\section{Highlights}

Phenyl-/aminoalkylsilane-grafted silica gels were used as supports for CaLB.

Adsorption onto mixed-function-grafted silica supports resulted in active CaLB.

CaLB adsorption and glutardialdehyde cross-linking resulted in enhanced durability.

The novel CaLB biocatalysts were used in kinetic resolutions of a secondary alcohol and an amine.

The novel CaLBs were robust biocatalysts in continuous-flow biotransformations.

\begin{abstract}
Adsorption onto solid supports has proven to be an easy and effective way to improve the mechanical and catalytic properties of lipases. Covalent binding of lipases onto the support surface enhances the active lifetime of the immobilized biocatalysts. Our study indicates that mesoporous silica gels grafted with various functions are ideal supports for both adsorptive and covalent binding for lipase B from Candida antarctica (CaLB). Adsorption of CaLB on phenyl-functionalized silica gels improved in particular its specific activity, whereas adsorption on aminoalkyl-modified silica gels enabling covalent binding with the proper reagents resulted in only moderate specific activity. In addition, adsorption on silica gels modified by mixtures of phenyl- and aminoalkyl silanes significantly increased the productivity of CaLB. Furthermore, CaLB adsorbed onto a phenyl/aminoalkyl-modified surface and then treated with glutardialdehyde (GDA) as cross-linking agent provided a biocatalyst of enhanced durability. Adsorbed and cross-linked CaLB was resistant to detergent washing that would otherwise physically deactivate adsorbed CaLB preparations. The catalytic properties of our best immobilized CaLB variants, including temperaturedependent behavior were compared between 0 and $70{ }^{\circ} \mathrm{C}$ with those of two commercial CaLB
\end{abstract}


biocatalysts in the continuous-flow kinetic resolutions of racemic 1-phenylethanol rac-1a and 1-phenylethanamine rac-1b.

\section{Introduction}

Enzyme-catalyzed transformations have gained ever increasing importance in modern synthetic processes [1], [2], [3] and [4]. The application of enzymes in their native forms, however, suffers several drawbacks. In aqueous solutions, enzymes are relatively unstable, and their recovery may be difficult due to their water solubility. Immobilization resulting in a reusable and stable heterogeneous phase form of the enzyme greatly extends the scope of their application in industrial processes [5] and [6]. Moreover, immobilized enzymes are recyclable, easy to store and handle and may show enhanced stability, activity and selectivity compared to their native forms [1], [7], [8], [9], [10], [11] and [12].

It was found that optimum performance of the immobilized enzymes in a given transformation may be attained by applying different enzyme immobilization strategies [13] and [14]. Therefore, the nature of the solid support in enzyme immobilization is particularly important [6], [11], [15] and [16]. Porous silica gels [15], [17], [18] and [19] and particularly mesoporous silica gels (MPSs) [20] and [21] have been shown to be useful carriers for enzyme immobilization due to their large surface area, tunable porosity, low cytotoxicity, favorable mechanical properties and functionalizable large surface. Modification by surface functionalization can widen their applicability as carriers for proteins and enzymes [20] and [21]. Cholesterol esterase (CE) combined with five different types of MPSs differing in structural properties such as pore diameter, pore volume, and particle morphology exhibited various catalytic activities [22]. Grafting the surface of MPSs of large pore size $(22.5 \mathrm{~nm})$ with various functions (such as decyl) resulted in improved immobilized CE biocatalysts with enhanced recyclability and thermal stability [22].

MPSs with amino functions on their surfaces enable either adsorptive or covalent immobilization. For example, an ordered MPS functionalized by post-synthesis grafting with (3-aminopropyl)triethoxysilane (APTEOS) was used for adsorptive immobilization of lipase from porcine pancreas (PPL), resulting in a higher hydrolytic activity and better reusability than when the enzyme was adsorbed on non-grafted MPS [23].

Amino functions on the surface of enzymes treated with suitable cross-linking agents such as glutardialdehyde (GDA) in the presence of a precipitant enable supportless immobilization by the preparation of cross-linked enzyme aggregates (CLEAs) which are efficient immobilized biocatalysts [24] even on an industrial scale [25].

In addition to immobilization, reactor technology may offer further means of upgrading of the efficacy of biotransformations. In recent years continuous-flow technology has received increasing attention and is becoming a promising alternative to batch processes [26] and [27]. Most of the continuous-mode biocatalytic syntheses of optically active chiral intermediates on a relatively large scale are performed using immobilized lipases in packed-bed reactors [28]. Stainless steel continuous-flow packed-bed bioreactors can be effectively used to study the effects of temperature, pressure and flow rate on stereoselective biotransformations such as lipase-catalyzed kinetic resolutions [29], [30], [31] and [32].

Among readily available lipases lipase B from Candida antarctica (CaLB) exhibits many attractive characteristics and has thus become one of the most widely used biocatalysts in both 
industrial applications and scientific research [3], [33], [34] and [35]. Recently, it was demonstrated that during the continuous-flow kinetic resolution of various amines using differently immobilized CaLB biocatalysts the character of the temperature effect in the range of $0-70{ }^{\circ} \mathrm{C}$ depended significantly both on the substrate and on the mode of immobilization [36].

Immobilization of CaLB on butyl- [37] or octyl-silica [19] and [38] has indicated the usefulness of surface-modified silica as lipase carrier. Surface-modified silica supports, especially butyl silica, have proven to be suitable carriers for CaLB-catalyzed reactions in ionic liquid/supercritical carbon dioxide biphasic media [39]. A study with a series of grafted silica gels indicated phenyl-silica as ideal support for CaLB securing satisfactory selectivity in the kinetic resolution of racemic 1-phenylethanol rac-1a, while the octyl-silica-adsorbed CaLB had poor activity with good enantiomer selectivity [40]. However, the aminopropylsilica adsorption resulted in CaLB biocatalysts of moderate performance [39].

Covalent immobilization of CaLB on amino-silica supports indicated that the thermal stability of such biocatalysts was better than those prepared by physical adsorption only [41]. CaLB adsorbed and cross-linked on a polypropylene carrier maintained its activity when dispersed in ionic liquids [42].

Coating an MPS with a mixture of the grafting reagents 4-aminophenyltrimethoxysilane and phenyltrimethoxysilane at different ratios demonstrated that the density of the amino groups present on the silica surface can be successfully controlled while keeping the overall number of grafts constant [43]. Thus, a simple method can secure tunable and even dispersion of amino functionality on the surface.

In the present work we set out to compare the usefulness of biocatalysts prepared by simple adsorption of CaLB with adsorption combined with cross-linking and covalent binding onto surface-functionalized silica supports with dispersed amino functions as novel biocatalysts in both in batch and continuous-flow mode.

\section{Materials and methods}

\subsection{Materials}

Racemic 1-phenylethanol (rac-1a), racemic 1-phenylethanamine (rac-1b), glutardialdehyde (GDA) solution $\left(25 \%\right.$, w/v in $\left.\mathrm{H}_{2} \mathrm{O}\right)$, vinyl acetate, sodium chloride, mono- and dibasic sodium phosphate, Trizma $^{\circledR}$ base (2-amino-2-hydroxymethyl-1,3-propanediol; Tris base), hydrochloric acid and Triton ${ }^{\mathrm{TM}}$ X-100 (4-(1,1,3,3-tetramethylbutyl)phenyl-polyethylene glycol) were purchased from Sigma-Aldrich.

Davisil $^{\circledR} 150$ [35-70 $\left.\mu \mathrm{m}\right]$ (Dv150), Davisil ${ }^{\circledR} 250$ [40-63 $\left.\mu \mathrm{m}\right]$ (Dv250), Daraclar ${ }^{\circledR} 915$ (Dc915) and Daraclar ${ }^{\circledR} 920$ (Dc920) were the products of Grace (Deerfield, USA). Geduran ${ }^{\circledR}$ Si $60[63-200 \mu \mathrm{m}]$ (Ged60) was purchased from Merck (Darmstadt, Germany). Silica supports functionalized with phenyltrimethoxysilane (PTMOS), octyltrimethoxysilane (OTMOS), (3-aminopropyl)trimethoxysilane [3-(2aminoethylamino)propyl]trimethoxysilane [3-(2aminoethylamino)propyl]methlydimethoxysilane (AEAP-MDMOS) and with various mixtures of such organosilanes were produced by SynBiocat Ltd (Budapest, Hungary). The labels for the functionalized silica supports indicate both the nature of the grafted silica gel 
and the grafting reagents. For example, Geduran ${ }^{\circledR} \mathrm{Si} 60$ grafted with OTMOS is labeled as Ged600 or Davisil ${ }^{\mathbb{R}} 250$ grafted with a PTMOS:AEAP-MDMOS 1:1 mixture is labeled as Dv250PAEAP11.

Novozym $^{\circledR} 435$ (CaLB N 435, recombinant lipase B from Candida antarctica expressed in Aspergillus niger and adsorbed on acrylic resin) and Novozym ${ }^{\circledR}$ CaLB L recombinant (lipase from Candida sp. expressed in Aspergillus niger with a protein content $\sim 4 \%, \geq 5000 \mathrm{LU} / \mathrm{g}$ ) were obtained from Sigma-Aldrich (Saint Louis, MO, USA). CaLB T2-150 (Candida antarctica lipase B covalently attached to dry acrylic beads with a $150-300 \mu \mathrm{m}$ particle size) was the product of ChiralVision BV (Leiden, The Netherlands).

Solvents (toluene, ethyl acetate, acetone, $n$-hexane, methyl tert-butyl ether, dichloromethane and 2-propanol) from Molar Chemicals (Budapest, Hungary) were dried and/or freshly distilled prior to use.

\subsection{Methods}

Thin-layer chromatography was carried out using Kieselgel $60 \mathrm{~F}_{254}$ (Merck) sheets. Spots were visualized under UV light (Vilber Lourmat VL-6.LC, $254 \mathrm{~nm}$ and $365 \mathrm{~nm}$ ) or by treatment with 5\% ethanolic phosphomolybdic acid solution and heating of the dried plates.

Reactions yielding 2a from 1a were analyzed by gas chromatography (GC) on Agilent 4890 equipment [FID: $250{ }^{\circ} \mathrm{C}$, injector: $250{ }^{\circ} \mathrm{C}$, carrier gas: $\mathrm{H}_{2}(12 \mathrm{psi})$, split ratio: 1:50] using a Hydrodex $\beta$-6TBDM column (Machery-Nagel, $25 \mathrm{~m} \times 0.25 \mathrm{~mm} \times 0.25 \mu \mathrm{m}$, heptakis-(2,3-di$O$-methyl-6-O-t-butyldimethylsilyl)- $\beta$-cyclodextrin); GC data (oven program: $120^{\circ} \mathrm{C}$, $8 \mathrm{~min}^{-1}$; molar response factor for $\left.\mathbf{2 a} / \mathbf{1 a}: 1.23\right): t_{\mathrm{r}}(\mathrm{min}): 4.0[(S)-\mathbf{2 a}], 4.4[(R)-\mathbf{2 a}], 5.8[(R)-$ 1a], 6.0 [(S)-1a. Reactions yielding $\mathbf{2 b}$ from $\mathbf{1 b}$ were analyzed on Agilent 5890 equipment [FID: $250{ }^{\circ} \mathrm{C}$, injector: $250{ }^{\circ} \mathrm{C}$, carrier gas: $\mathrm{H}_{2}(12 \mathrm{psi})$, split ratio: 1:50] using a Hydrodex $\beta$ TBDAc column (Machery-Nagel; $25 \mathrm{~m} \times 0.25 \mathrm{~mm} \times 0.25 \mu \mathrm{m}$, heptakis-(2,3-di-O-acetyl-6-O$t$-butyl-dimethylsilyl)- $\beta$-cyclodextrin); GC data (oven program: $100-180{ }^{\circ} \mathrm{C}, 8{ }^{\circ} \mathrm{C} \mathrm{min}{ }^{-1}$, $5 \mathrm{~min}$ at $180{ }^{\circ} \mathrm{C}$; molar response factor for $\left.\mathbf{2 b} / \mathbf{1 b}: 1.17\right): t_{r}(\mathrm{~min}): 2.9$ [(S)-1b], $3.1[(R)-\mathbf{1 b}]$, $9.8[(R)-\mathbf{2 b}], 10.0[(S)-\mathbf{2 b}]$. All data in Tables and Figures arose from a precise integration of chromatograms in which both enantiomers of the substrates $\mathbf{1 a}, \mathbf{b}$ and the products $\mathbf{2 a}, \mathbf{b}$ were clearly visible. When peaks for the minor enantiomers were indistinguishable from noise, solid curves were replaced by dashed lines in Fig. 4 and Fig. 5.

Conversion $(c)$, enantiomeric excess (ee) and enantiomeric ratio $(E)$ were determined by GC. Enantiomeric ratio $(E)$ was calculated from $c$ and enantiomeric excess of the product $\left(e e_{\mathrm{P}}\right)$ using the equation $E=\ln \left[1-c\left(1+e e_{\mathrm{P}}\right)\right] / \ln \left[1-c\left(1-e e_{\mathrm{P}}\right)\right]$ [44]. Due to its sensitivity to experimental error $E$ values in the 100-200 range are given as $>100$, in the range of $200-500$ as $>200$ and above 500 as $\gg 200$.

In batch reactions, the specific activity of the biocatalyst $\left(U_{\mathrm{B}}\right)$ was determined using the equation $U_{\mathrm{B}}=\left(n_{\mathrm{rac}} \times c\right) /\left(t \times m_{\mathrm{B}}\right)$ [32]. To characterize the productivity of the biocatalysts, the specific reaction rates in the batch reactions $\left(r_{\text {batch }}\right)$ were calculated using the equation $r_{\text {batch }}=n_{\mathrm{P}} /\left(t \times m_{\mathrm{B}}\right)$ (where $n_{\mathrm{P}}[\mu \mathrm{mol}]$ is the amount of the product, $t$ [min] is the reaction time and $m_{\mathrm{B}}$ [g] is the mass of the biocatalyst) [44]. Specific reaction rates in continuous-flow systems $\left(r_{\text {flow }}\right)$ were calculated using the equation $r_{\text {flow }}=[P] \times v / m_{\mathrm{B}}\left(\right.$ where $[P]\left[\mu \mathrm{mol} \mathrm{mL}{ }^{-1}\right]$ is the molar concentration of the product, $v\left[\mathrm{~mL} \mathrm{~min}^{-1}\right]$ is the flow rate and $m_{\mathrm{B}}[\mathrm{g}]$ is the mass of the biocatalyst) [44]. Because the rate of product formation is not a linear function of $c$, 
rigorous comparisons by the $r$ values between the productivity of a continuous-flow reaction and its batch mode counterpart can only be made at similar degrees of conversions [44].

\subsection{General procedure for lipase adsorption to silica supports}

CaLB L (1.25 mL, $\geq 6250 \mathrm{LU} / \mathrm{g}, \sim 5 \mathrm{mg}$ protein) was dissolved in Tris buffer $(11.25 \mathrm{~mL}$, $100 \mathrm{mM}, \mathrm{pH}=7.5$, ionic strength controlled with $\mathrm{NaCl}$ to $175 \mathrm{mM}$ ), an then the support $(250 \mathrm{mg})$ was added to the solution. The enzyme-support suspension was incubated at $400 \mathrm{rpm}$ and $4{ }^{\circ} \mathrm{C}$ for $18 \mathrm{~h}$. The immobilized CaLB was filtered off on glass filter (G4), washed with 2-propanol $(2 \times 5 \mathrm{~mL})$ and hexane $(5 \mathrm{~mL})$, dried for $2 \mathrm{~h}$ at room temperature and stored at $4{ }^{\circ} \mathrm{C}$. The properties of CaLBs immobilized by adsorption are shown in Table 1 (Entries 2-16), Table 2 (Entries 2-4) and Table 3 (Entries 1-9). The labels of the CaLB biocatalysts immobilized by adsorption indicate the nature of support and the mode of immobilization. For example, CaLB adsorbed on Ged60P is labeled as CaLB Ged60P-A or CaLB adsorbed on Dv250PAP31 support is labeled as CaLB Dv250PAP31-A.

\subsection{Cross-linked enzyme aggregates (CLEA) from Candida antarctica B lipase}

Cross-linked CaLB aggregates were prepared using the slightly modified method of LópezSerrano et al. [45]. To a mixture of liquid CaLB L $(1.0 \mathrm{~mL})$ and phosphate buffer $(2 \mathrm{~mL}$, $0.1 \mathrm{M}, \mathrm{pH}=7.5)$ acetone $(6 \mathrm{~mL})$ and GDA solution $(160 \mu \mathrm{L})$ were added subsequently. The mixture was incubated at $400 \mathrm{rpm}$ and $4{ }^{\circ} \mathrm{C}$ for $17 \mathrm{~h}$. After addition of more acetone $(2 \mathrm{~mL})$, the resulting slurry was centrifuged $(50 \mathrm{~mL}$ PP Corning centrifuge tubes, $3500 \mathrm{rpm}$, $\sim 2000 \times g, 7^{\circ} \mathrm{C}, 20 \mathrm{~min}$, Hermle Z400 K). The supernatant was decanted and the residue was washed with acetone $(3 \times 10 \mathrm{~mL})$, centrifuged $\left(3500 \mathrm{rpm}, \sim 2000 \times g, 7^{\circ} \mathrm{C}, 20 \mathrm{~min}\right)$ and decanted. The resulting preparation was dried at room temperature for $0.5 \mathrm{~h}$ and stored at $4{ }^{\circ} \mathrm{C}$. The properties of CaLB CLEA are shown in Table 2 (Entry 1 ).

\subsection{Cross-linking and covalent binding of CaLB onto silica supports}

Cross-linked CaLB preparations on silica supports were produced using a process similar to that described in Section 2.4 with the exception of the addition of adsorbed CaLB preparations [Table 2 (Entries 2-4) and Table 3 (Entries 1-9)] instead of CaLB L. Thus, acetone $(6 \mathrm{~mL})$ and GDA solution $(160 \mu \mathrm{L})$ were added to the suspension of silica-supported CaLB (100 mg) in a phosphate buffer $(2 \mathrm{~mL}, 0.1 \mathrm{M}, \mathrm{pH}=7.5)$ and the mixture was shaken at $400 \mathrm{rpm}$ and $4{ }^{\circ} \mathrm{C}$ for $17 \mathrm{~h}$. After the addition of acetone $(2 \mathrm{~mL})$, the suspension was centrifuged (50 mL PP Corning centrifuge tubes, $3500 \mathrm{rpm}, \sim 2000 \times g, 7^{\circ} \mathrm{C}, 20 \mathrm{~min}$, Hermle $\mathrm{Z} 400 \mathrm{~K})$. The supernatant was decanted and the residue was washed with acetone $(3 \times 10 \mathrm{~mL})$, centrifuged $\left(3500 \mathrm{rpm}, \sim 2000 \times \mathrm{g}, 7^{\circ} \mathrm{C}, 20 \mathrm{~min}\right)$ and decanted. The enzyme preparation was dried for $0.5 \mathrm{~h}$ at room temperature and stored at $4{ }^{\circ} \mathrm{C}$. The properties of CaLBs immobilized by cross-linking and covalent binding to amino-grafted silica supports are shown in Table 2 (Entries 5-7) and Table 3 (Entries 10-18). The labels of the CaLB biocatalysts immobilized by adsorption and cross-linking also indicate the nature of support and the mode of immobilization. For example, CaLB adsorbed and cross-linked on Dv250AP support is labeled as CaLB Dv250AP-C or CaLB adsorbed and cross-linked on Dv250PAP31 support is labeled as CaLB Dv250PAP31-C. 


\subsection{Enzyme desorption tests}

Samples of the CaLB biocatalysts (100 mg each) were treated at room temperature for $1.5 \mathrm{~h}$ with a phosphate buffer $(5 \mathrm{~mL} ; 100 \mathrm{mM} ; \mathrm{pH}=7.5)$ or a $2 \%(\mathrm{v} / \mathrm{v})$ solution of Triton $\mathrm{X}-100$ in the same buffer $(5 \mathrm{~mL})$ in a shaker at $400 \mathrm{rpm}$. The samples were then filtered on a glass filter (G4) and washed with distilled water $(2 \times 5 \mathrm{~mL}$; only for the Triton X-100 treated samples), 2-propanol $(2 \times 5 \mathrm{~mL})$ and hexane $(5 \mathrm{~mL})$.

\subsection{Packed-bed columns filled with immobilized CaLB}

Immobilized CaLBs [CaLB N 435, CaLB T2-150, CaLB Dv250P (Table 1, Entry 15), CaLB Dv250PAP13-A (Table 3, Entry 3) and CaLB Dv250PAP13-C (Table 3, Entry 12)] were packed into stainless steel CatCart ${ }^{\mathrm{TM}}$ columns $(70 \mathrm{~mm} \times 4 \mathrm{~mm})$ according to the filling procedure of ThalesNano Inc. Before packing, the columns were washed with distilled water, ethanol, $n$-hexane and acetone in ultrasonic cleaner. The columns were capped with silver metal filter membranes [Sterlitech Silver Membrane Filter from Sigma-Aldrich, Z623237, pore size $0.45 \mu \mathrm{m}$; pure metallic silver, $99.97 \%$ purity with no extractable or detectable contaminants]. The known benefit of $\mathrm{Ag}$ is its bacteriostatic activity. Sealings were made by PTFE. Three CatCart ${ }^{\mathrm{TM}}$ columns per enzyme (separate columns for each substrate, rac-1a and rac-1b) were packed (filling weights: CaLB N 435, $282 \pm 14 \mathrm{mg}$; CaLB T2-150, $262 \pm 3 \mathrm{mg}$; CaLB Dv250P, $247 \pm 6 \mathrm{mg}$; CaLB Dv250PAP13-A, $260 \pm 25 \mathrm{mg}$ and CaLB Dv250PAP13-C, $288 \pm 5 \mathrm{mg})$.

\subsection{Kinetic resolution of racemic 1-phenylethanol rac-1a in batch mode}

Immobilized CaLB $(50 \mathrm{mg})$ was added to a solution of the racemic 1-phenylethanol rac-1a $(50 \mu \mathrm{l} ; 50.6 \mathrm{mg} ; 0.41 \mathrm{mmol})$ in hexane/methyl $t$-butyl ether/vinyl acetate $6 / 3 / 1(\mathrm{v} / \mathrm{v})$ mixture $(1 \mathrm{~mL})$ in a screw-capped amber glass vial and the resulting mixture was shaken $(1000 \mathrm{rpm})$ at $30^{\circ} \mathrm{C}$ for $4 \mathrm{~h}$. Samples $(10 \mu \mathrm{L})$ from each reactions were taken at $4 \mathrm{~h}$ for silica support screening (Table 1) and at 1, 2 and $4 \mathrm{~h}$ for further tests. After dilution with dichloromethane $(250 \mu \mathrm{L})$, the samples were analyzed by GC as described in Section 2.2.

\subsection{Kinetic resolution of racemic 1-phenylethanol rac-1a and racemic 1- phenylethanamine rac-1b in continuous-flow bioreactor}

Continuous-flow kinetic resolutions were performed in a laboratory flow reactor built from a Knauer K-120 isocratic HPLC pump attached to CatCart ${ }^{\mathrm{TM}}$ columns filled with the immobilized CaLB biocatalysts in an in-house made aluminum metal block column holder with precise temperature control. The CaLB-filled columns were washed with a dry hexane/methyl $t$-butyl ether $2 / 1$ mixture $\left(0.5 \mathrm{~mL} \mathrm{~min}^{-1}, 20 \mathrm{~min}\right)$ before reactions with $\mathrm{rac}-1 \mathbf{a}$ or a dry toluene/ethyl acetate $9 / 1$ mixture $\left(0.5 \mathrm{~mL} \mathrm{~min}^{-1}, 20 \mathrm{~min}\right)$ before reactions with rac$1 \mathrm{~b}$.

The solution of racemic 1-phenylethanol rac-1a $\left(10 \mathrm{mg} \mathrm{mL}^{-1} ; 0.082 \mathrm{M}\right)$ in dry hexane/methyl $t$-butyl ether/vinyl acetate $6 / 3 / 1$ or racemic 1-phenylethanamine rac-1b $\left(10 \mathrm{mg} \mathrm{mL}^{-1}\right.$; $0.083 \mathrm{M}$ ) in dry toluene/ethyl acetate $9 / 1$ were pumped through the enzyme-filled column set to various temperatures $\left(0-70{ }^{\circ} \mathrm{C}\right)$ at a flow rate of $0.4 \mathrm{~mL} \mathrm{~min}{ }^{-1}$ for rac-1a or $0.2 \mathrm{~mL} \mathrm{~min}{ }^{-1}$ for rac-1b. Samples were analyzed by GC every $10 \mathrm{~min}$ up to $40 \mathrm{~min}$ to allow the establishment of a stationary state. Samples were collected during stationary operation (30 min after changing the parameters) and analyzed as described in Section 2.2. 
After completing experiments at a series of temperatures $\left(0-70{ }^{\circ} \mathrm{C}\right.$ in $10{ }^{\circ} \mathrm{C}$ steps $)$, the columns were routinely washed with hexane $\left(0.5 \mathrm{~mL} \mathrm{~min}^{-1}, 20 \mathrm{~min}\right.$, for reactions with rac1a) or toluene $\left(0.5 \mathrm{~mL} \mathrm{~min}{ }^{-1}, 20 \mathrm{~min}\right.$, for reactions with $\left.\mathrm{rac}-\mathbf{1 b}\right)$ and then stored at $4{ }^{\circ} \mathrm{C}$.

\section{Results and discussion}

In this study our aim was to evaluate various immobilization methods of lipase B from Candida antarctica using adsorption and adsorption combined with cross-linking and covalent binding onto surface functionalized silica supports with dispersed amino functions and to compare our best performing novel biocatalysts with those prepared by other immobilization procedures in both batch and continuous-flow modes.

\subsection{Selection of silica gel supports}

First, the performance of five silica gels with different particle sizes and pore diameters [Davisil $^{\circledR}$ 150: 35-70 $\mu \mathrm{m}, 150 \AA$ (Dv150); Davisil ${ }^{\circledR}$ 250: 40-63 $\mu \mathrm{m}, 250 \AA$ (Dv250); Daraclar $^{\circledR} 915$ (Dc915); Daraclar ${ }^{\circledR} 920$ (Dc920); and Geduran ${ }^{\circledR}$ Si 60: 63-200 $\mu \mathrm{m}, 60 \AA$ (Ged60)] and their octyl- and phenyl-grafted variants were tested as inorganic support for adsorption of CaLB from a buffer $(100 \mathrm{mM}$ Tris, $\mathrm{pH}=7.5)$ solution. The catalytic performance of the resulting biocatalysts was characterized by the kinetic resolution of racemic-1-phenylethanol rac-1a (Table 1).

Specific activity values of our biocatalysts $\left(U_{\mathrm{B}}\right.$, at $\left.4 \mathrm{~h}\right)$ compared with that of an efficient commercial version of immobilized CaLB $\left(\mathrm{N} 435: U_{\mathrm{B}}=17.7 \mathrm{U} \mathrm{g}^{-1}\right)$ indicated that some of our silica gel-based CaLB preparations already performed similarly (e.g., Dv250P: $U_{\mathrm{B}}=16.6 \mathrm{U} \mathrm{g}^{-1}$ or Dc915P: $U_{\mathrm{B}}=16.4 \mathrm{U} \mathrm{g}^{-1}$ ). In accordance with our recent result on the adsorptive immobilization of CaLB onto various hydrophobic silica gels [36] in the kinetic resolution of rac-1a, CaLB on phenyl-grafted silica supports was always more active than that adsorbed on octyl-grafted silica. Surprisingly, with the exception of DV150, CaLB on untreated silica supports resulted in more active biocatalysts than those on octyl-grafted silica. Although CaLB adsorption on the phenyl-grafted versions of silica materials designed for protein removal in breweries (Dc915 and Dc920) gave quite active and selective biocatalysts, their usefulness in synthetic biotransformations is limited due to their rather small particle size. Because the best overall performance was achieved by CaLB adsorbed on phenyl-grafted mesoporous silica gel (Dv250P: pore diameter $250 \AA$ ), Dv250 was chosen as the support for further investigations.

\subsection{CaLB immobilization by adsorption and adsorption combined with cross-linking on amino-functionalized silica gels}

Our further goal was to combine the benefits of adsorption and covalent binding onto aminosilica and to prepare cross-linked enzyme aggregates and in this way to further improve the stability of immobilized CaLB. It was shown that covalent immobilization of CaLB on amino-silica resulted in better thermal stability of the enzyme than simple physical adsorption [41]. In addition, CaLB adsorbed and cross-linked on a polypropylene carrier also exhibited advantageous properties [42]. It was therefore assumed that adsorption on a proper support carrying amino functions followed by GDA cross-linking may provide a more stable crosslinked CaLB that is also attached at the same time to the support by covalent bonds. As a first approach, a Dv250 support was grafted with (3-aminopropyl)trimethoxysilane (APTMOS), [3-(2-aminoethylamino)propyl]trimethoxysilane (AEAPTMOS) and [3-(2- 
aminoethylamino)propyl]methlydimethoxysilane (AEAP-MDMOS) and the amino-silica supports thus obtained were tested with CaLB for adsorption (A) and adsorption followed by GDA cross-linking (C) (Table 2). The resulting CaLB preparations were also compared with non-supported CLEA of CaLB (Table 2). Adsorption of CaLB on amine-functionalized silica gels (method A in Table 2) gave less useful biocatalysts than adsorption on phenyl silica (e.g., $E \gg 200$ of Dv250P-A vs. E $>200$ with Dv250AP-A). A further significant drop of specific activity was found when adsorption was combined with GDA cross-linking on aminefunctionalized silica gels (method $\mathrm{C}$ in Table 2).

\subsection{Adsorption and adsorption combined with cross-linking and covalent binding of CaLB onto mixed-function-grafted silica gels containing dispersed amino moieties}

A simple one-pot process of grafting mesoporous silica gel with a mixture of aminofunctionalized and amine-free silanes at different ratios indicated that it is possible to control the dispersion of functionality present on the silica surface [43]. This finding combined with the promising adsorption results of hydrophobic grafting of silica gel (Table 1) led to the conclusion that the moderate performance involving adsorption (A) and adsorption combined with GDA cross-linking (C) onto aminoalkyl-grafted silica supports (Table 2) can be improved by dispersing the aminoalkyl functions with the best performing phenyl-grafting. Accordingly, three mixed-grafting series were prepared using mixtures of PTMOS:APTMOS, PTMOS:AEAPTMOS and PTMOS:AEAP-MDMOS (at ratios of 3:1, 1:1 and 1:3 in each series) for surface modification, and the resulting phenyl-dispersed amino-silica supports were tested for adsorption (A) and for adsorption and GDA cross-linking/covalent binding (C) with CaLB (Table 3).

Compared to the solely aminoalkyl-grafted variants, adsorption of CaLB on the dispersedamino-silica supports (method A in Table 3) resulted in higher productivity (e.g., $U_{\mathrm{B}}=17.1 \mathrm{U} \mathrm{g}^{-1}$ of Dv250AP-A raised to $U_{\mathrm{B}}=57.0,59.9$ and $60.5 \mathrm{U} \mathrm{g}^{-1}$ with Dv250PAP13A, Dv250PAP11-A and Dv250PAP31-A, respectively) and higher selectivity (e.g., E $>200$ of Dv250AP-A raised to $E \gg 200$ for all three Dv250PAP-A biocatalysts). Adsorption of CaLB onto supports with a grafting mixture with higher phenyl content gave more productive biocatalysts within all three series (method A in Table 3).

The positive effect of dispersing the amino functions with the aid of phenyl moieties on the productivity of the biocatalysts was even more pronounced when adsorption of CaLB onto the supports was combined with GDA cross-linking (method C in Table 3: e.g., $U_{\mathrm{B}}=4.2 \mathrm{U} \mathrm{g}^{-1}$ of Dv250AP-C raised to $U_{\mathrm{B}}=16.4,29.9$ and $44.0 \mathrm{U} \mathrm{g}^{-1}$ with Dv250PAP13-C, Dv250PAP11-C and Dv250PAP31-C, respectively), and selectivity was maintained at a satisfactory level $(E>100)$. Within all three aminoalkyl-phenyl series (aminoalkyl-phenyl ratios of 3:1, 1:1 and 1:3) a higher phenyl content proved to be the best (e.g., $U_{\mathrm{B}}=16.4 \mathrm{U} \mathrm{g}^{-1}$ of Dv250PAP13$\mathrm{C}$ increased to $U_{\mathrm{B}}=44.0 \mathrm{U} \mathrm{g}^{-1}$ with Dv250PAP31-C and $E>100$ with Dv250PAP13-C increased to $E>200$ with Dv250PAP31-C).

However, adsorption combined with GDA cross-linking and covalent binding (C) compared with adsorption (A) onto mixed-function-grafted silica gel supports resulted in a slight reduction of productivity (e.g., $U_{\mathrm{B}}=60.5 \mathrm{U} \mathrm{g}^{-1}$ of Dv250PAP31-A vs. $U_{\mathrm{B}}=44.0 \mathrm{U} \mathrm{g}^{-1}$ with Dv250PAP31-C) and selectivity ( $E \gg 200$ with Dv250PAP31-A vs. $E>200$ with Dv250PAP31-C). 


\subsection{Morphology of the variously immobilized CaLB biocatalysts}

To gain further insight into the behavior of the novel biocatalysts, the best performing silicabased CaLB biocatalysts from the present study, i.e. Dv250P-A, Dv250PAP31-A and Dv250PAP31-C were compared with the commercial forms of CaLB namely $\mathrm{N} 435$ (adsorption on acrylic beads) and T2-150 (covalent binding onto acrylic beads) by scanning electron microscopy (SEM) (Fig. 1). Analysis at 150× magnification revealed the expected particle sizes of the various CaLB preparations $(\sim 500 \mu \mathrm{m}$ for $\mathrm{N} 435,150-300 \mu \mathrm{m}$ for $\mathrm{T} 2-150$, and 35-90 $\mu \mathrm{m}$ for Dv250P-A, DV250PAP31-A and DV250PAP31-C) and no particle aggregations in all cases. Notably it was the pore structure and the available surface area and not the particle size that most influenced the activity of immobilized enzymes. Larger magnifications (1000-3000×) indicated uniform surface coverage of the two commercial CaLB preparations (N 435 and T2-150) and also of the two silica-based CaLBs immobilized by adsorption (Dv250P-A and Dv250PAP31-A). In contrast, adsorption combined with crosslinking (Dv250PAP31-C) resulted in the formation of a non-homogeneous surface with attached aggregated protein particles. Increased limitation of diffusion within these aggregates of $0.5-2 \mu \mathrm{m}$ size may explain the diminished specific activity of Dv250PAP31-C CaLB compared with Dv250PAP31-A CaLB.

\subsection{Desorption behavior of the various immobilized CaLB biocatalysts}

In addition to SEM studies, the CaLB preparations N 435, T2-150, Dv250P-A, Dv250PAP31A and Dv250PAP31-C were investigated in enzyme desorption tests. The biocatalysts were treated for $1.5 \mathrm{~h}$ at room temperature with phosphate buffer $(100 \mathrm{mM} ; \mathrm{pH}=7.5)$ and separately with a $2 \%(\mathrm{v} / \mathrm{v})$ solution of Triton X-100 in the same buffer (Fig. 2). Although three of the five CaLB biocatalysts tested (N 435, Dv250P-A and Dv250PAP31-A) were immobilized only by physical adsorption, all of them retained at least $66 \%$ of their initial specific activity $\left(U_{\mathrm{B} 0}\right)$ after treatment with phosphate buffer. Interestingly, treatment with phosphate buffer only even led to enhanced specific activity $\left(U_{\mathrm{B}} / U_{\mathrm{B} 0}=143 \%\right.$ and $105 \%$ for T2-150 and Dv250P-A CaLB, respectively). However, all of the CaLB biocatalysts immobilized by physical adsorption only (N 435, Dv250P-A and Dv250PAP31-A) lost at least $50 \%$ of their initial specific activity $\left(U_{\mathrm{B} 0}\right)$ upon treatment with $2 \%$ Triton $\mathrm{X}-100$. The most durable CaLB biocatalyst against Triton X-100 desorption was Dv250PAP31-C, an adsorbed and GA cross-linked CaLB bound to aminopropyl-phenyl-grafted silica, which retained $83 \%$ of its initial activity. This high degree of stability of Dv250PAP31-C CaLB may compensate for its lower degree of activity compared with that of the most active Dv250PAP31-A CaLB (Dv250PAP31-C: $\quad U_{\mathrm{B}}=44.0 \mathrm{U} \mathrm{g}^{-1}, \quad$ Dv250PAP31-A: $\left.U_{\mathrm{B}}=60.5 \mathrm{U} \mathrm{g}^{-1}\right)$.

\subsection{Performance of the variously immobilized CaLB biocatalysts in the kinetic resolution of the alcohol rac-1a and the amine rac-1b}

A recent study demonstrated that the various modes of immobilization of CaLB significantly influenced the character of the temperature effect on the catalytic properties of the enzyme in continuous-flow kinetic resolution of racemic amines [36]. Our further aim was now to extend our investigations on the temperature dependence of $O$-acylation with various forms of $\mathrm{CaLB}$ 
as well (Fig. 3). Therefore the temperature effect (in the range of $0-70{ }^{\circ} \mathrm{C}$ ) was studied with our best-performing novel mixed-function-grafted silica gel-based CaLBs on the continuousflow kinetic resolution of a typical alcohol such as racemic 1-phenylethanol rac-1a (Fig. 4) and a typical amine such as 1-phenylethanamine rac-1b (Fig. 5).

Five differently immobilized forms of CaLB were selected for the continuous-flow studies. The silica gel-based Dv250P-A (adsorption onto phenyl silica), Dv250PAP31-A (adsorption onto silica grafted with a PTMOS-APTMOS 3:1 mixture) and Dv250PAP31-C (adsorption and glutardialdehyde cross-linking onto silica grafted with a PTMOS-APTMOS 3:1 mixture) forms of CaLB were compared with Novozym ${ }^{\circledR} 435$ (CaLB N 435, adsorption onto acrylic resin) and CaLB T2-150 (covalently attached to acrylic beads). In this way, a diverse selection of various immobilization methods (adsorption on inorganic and organic supports, covalent attachment on polymeric support and mixed-mode adsorption and GA cross-linking) of CaLB was covered.

In the continuous-flow kinetic resolutions of 1-phenylethanol rac-1a between 0 and $70{ }^{\circ} \mathrm{C}$, significant alterations in the biocatalytic properties of the variously immobilized CaLBs were observed (Fig. 4). Productivity (specific reaction rate, $r_{\text {flow }}$ ) change in the acylation of rac-1a followed a sigmoid (Dv250P-A) or a hyperbolically ascending curve (Dv250PAP31-A and N $435)$ for the physically adsorbed CaLBs, whereas a hyperbolically ascending increase in $r_{\text {flow }}$ was found for the covalently bound and for the adsorbed and covalently cross-linked CaLBs (T2-150 and Dv250PAP31-C) representing conformationally more-restricted forms of the enzyme.

The effect of enzyme flexibility was even more significant on the selectivity of the kinetic resolutions of rac-1a. The physically adsorbed, conformationally more flexible CaLBs (Dv250P-A, Dv250PAP31-A and N 435) behaved similarly and showed selectivity maxima at approximately $20^{\circ} \mathrm{C}$ (curves for $e e_{(R)-2 \mathrm{c}}$ and $E$ in Fig. 4). Conformational restrictions of the enzyme in the covalently bound CaLBs (Dv250PAP31-C and T2-150) resulted in a significant loss of selectivity. Thus, e.g. $e e=99.65 \%$ and $E \sim 700$ at $20^{\circ} \mathrm{C}$ was found for Dv250PAP31C compared with the only adsorbed and therefore less-restricted CaLBs, e.g., Dv250PAP31A, with $e e=99.87 \%$ and $E \sim 2000$ at $20^{\circ} \mathrm{C}$. Although the nature of the selectivity change as a function of temperature with covalently bound CaLBs (Dv250PAP31-A and T2-150) remained similar with a maximum, these maxima shifted toward higher temperatures (at approximately $30-40{ }^{\circ} \mathrm{C}$ ). The beneficial stabilization effect of cross-linking became obvious at $70{ }^{\circ} \mathrm{C}$ where the Dv250PAP31-C form of CaLB retained the highest enantiomer selectivity (ee $=99.5 \%$ and $E \sim 750$ ) among all of the five CaLB forms.

For the continuous-flow kinetic resolutions of 1-phenylethanol rac-1a, the catalytic activity of the CaLB N435 chosen as a standard was higher $\left(r_{\text {flow }}=37.2 \mu \mathrm{mol} \mathrm{min}{ }^{-1} \mathrm{~g}^{-1}\right.$ at $20{ }^{\circ} \mathrm{C}$ in a hexane/methyl $t$-butyl ether/vinyl acetate 6/3/1 mixture with rac-1a) than that found earlier $\left(r_{\text {flow }}=10.2 \mu \mathrm{mol} \mathrm{min} \mathrm{g}^{-1}\right.$ at $25^{\circ} \mathrm{C}$ in a hexane-THF-vinyl acetate $2: 1: 1$ mixture with rac1a[29]. The reusability of the supported biocatalysts investigated in this work was similar as found earlier [29], [30], [31] and [32]. For example, no significant drop of activity was observed with the CaLB N435 packed in CatCart column after a series of 12 reactions performed in continuous-flow biotransformations at various temperatures and pressures between $0-60{ }^{\circ} \mathrm{C}$ and $1-120$ bar (60 min, each; followed by a 30 min long washing) [29]. It should be noted here that such precise recovery of activity with $\sim 0.4 \mathrm{~g}$ enzyme is hardly possible with batch mode reactions due to the mechanical damage of the biocatalyst even on shaking and due to the loss of biocatalyst during filtrations. 
Although the particle size of the silica gel-based CaLB preparations $(35-90 \mu \mathrm{m}$ for Dv250PA, DV250PAP31-A and DV250PAP31-C) was much smaller than that for CaLBs based on a polymeric support ( $\sim 500 \mu \mathrm{m}$ for $\mathrm{N} 435,150-300 \mu \mathrm{m}$ for $\mathrm{T} 2-150)$, the pressure drop observed on a $70 \mathrm{~mm}$ long CatCart ${ }^{\mathrm{TM}}$ column was negligible ( $<2$ bar).

In the continuous-flow kinetic resolutions of 1-phenylethanamine rac-1b at $0-70{ }^{\circ} \mathrm{C}$, productivity (specific reaction rate, $r_{\text {flow }}$ ) changes of the variously immobilized CaLBs were different as well (Fig. 5). The $r_{\text {flow }}$ in $N$-acylation of rac-1b followed sigmoid (T2-150 and Dv250P-A) or hyperbolically ascending curves (Dv250PAP31-A, Dv250PAP31-C and N 435). In general, $r_{\text {flow }}$ for the $N$-acylation of $r a c-1 \mathbf{b}$ with ethyl acetate (Fig. 5) was lower than in the corresponding $\mathrm{O}$-acylation of rac-1a with vinyl acetate (Fig. 4) for all forms of CaLB.

However, enantiomer selectivity at temperatures up to $50{ }^{\circ} \mathrm{C}$ for the $\mathrm{N}$-acylation of rac-1b with ethyl acetate (Fig. 5) was higher than that of the corresponding $O$-acylation of rac-1a with vinyl acetate (Fig. 4) for all forms of CaLB. In accordance with the results of the $O$ acylation of rac-1a (Fig. 4), conformational restrictions of the enzyme in the covalently bound CaLBs (Dv250PAP31-C and T2-150) resulted in lower enantiomer selectivity in the kinetic resolutions of rac-1b compared with the physically adsorbed forms (Dv250PAP31-A, Dv250PAP31-C and $\mathrm{N} \mathrm{435).} \mathrm{Interestingly,} \mathrm{in} \mathrm{all} \mathrm{instances,} \mathrm{the} \mathrm{drop} \mathrm{of} \mathrm{the} \mathrm{enantiomer}$ selectivity during $N$-acylation of $\mathrm{rac}-\mathbf{1 b}$ above $50{ }^{\circ} \mathrm{C}$ was more pronounced than in the kinetic resolutions of rac-1b with the same form of CaLB.

\section{Conclusions}

Our study indicates that adsorption and adsorption combined with cross-linking onto mesoporous silica gels grafted with various functions were advantageous immobilization methods for Candida antarctica lipase B (CaLB). Silica gels modified with mixtures of phenyl- and aminoalkyl silanes were better supports for CaLB than those grafted by only one of the components. Particularly, the productivity $\left(U_{\mathrm{B}}\right.$, in batch mode or $r_{\text {flow }}$, in continuousflow mode) of the CaLB biocatalyst was enhanced by adsorption onto phenyl/aminoalkylmodified silica supports. Compared with the adsorbed CaLBs, the biocatalysts showed enhanced durability and a higher degree of enantiomer selectivity at elevated temperatures (above $60^{\circ} \mathrm{C}$ ) with acceptable productivity when CaLB was adsorbed and cross-linked on silica gels modified with mixtures of phenyl- and aminoalkyl silanes.

The study of the temperature-dependent behavior of the variously immobilized forms of CaLB between 0 and $70^{\circ} \mathrm{C}$ during continuous-flow kinetic resolutions of racemic 1phenylethanol 1a and racemic 1-phenylethanamine 1b indicated that the optimal method of immobilization depended on both the nature of the substrate and the reaction conditions. If higher productivity and selectivity at lower temperatures is important, then immobilization by adsorption onto mixed-function-grafted silica gel supports is preferred. If, however, enhanced stability and preserved selectivity at elevated temperatures are more important, adsorption combined with glutardialdehyde cross-linking on the same support should be used.

\section{Acknowledgements}


This research work was part of the "Development of quality-oriented and harmonized $\mathrm{R}+\mathrm{D}+\mathrm{I}$ strategy and functional model at BME" project (TÁMOP-4.2.1/B-09/1/KMR-20100002), supported by the New Hungary Development Plan. We thank Thales Nanotechnology Inc. for fillable CatCart ${ }^{\circledR}$ columns.

\section{References}

\section{L. Poppe, L. Novák}

Selective biocatalysis: a synthetic approach

VCH, Weinheim/New York (1992)

2. H.J. Rehm, G. Reed, A. Pühler, P. Stadler, D.R. Kelly (Eds.), Biotechnology:

biotransformations I and II, vols. 8a and 8b (2nd ed.), Wiley-VCH, Weinheim (1998)

3. J. Whittall, P. Suton (Eds.), Practical methods for biocatalysis and biotransformations, Wiley, Chicester (2010)

4. K. Faber

Biotransformations in organic chemistry

(6th ed.)Springer, Berlin (2011)

5. A. Ballesteros, G. van Beynum, O. Borud, K. Buchholz

Guidelines for the characterization of immobilized biocatalysts

Enzyme Microb Technol, 5 (1983), pp. 304-307

6. (a) R.A. Messing (Ed.), Immobilized enzymes for industrial reactors, Academic Press, New York (1975)

(b) ,in: J.M. Guisan (Ed.), Immobilization of Enzymes and Cells, Methods in

Biotechnology (2nd ed.), vol. 22, Humana Press, Totowa, NJ (2006)

7. K.W. Lee, K. Min, K. Park, Y.J. Yoo

Development of an amphiphilic matrix for immobilization of Candida antartica lipase B for biodiesel production

Biotechnol Bioprocess Eng, 15 (2010), pp. 603-607

8. C.J. Mateo, M. Palomo, G. Fernandez-Lorente, J.M. Guisan, R. Fernandez-Lafuente Improvement of enzyme activity, stability and selectivity via immobilization techniques Enzyme Microb Technol, 40 (2007), pp. 1451-1463

9. L.E. Rodgers, R.B. Knott, P.J. Holden, K.J. Pike, J.V. Hanna, L.J.R. Foster et al.

Structural evolution and stability of sol-gel biocatalysts

Physica B, 386 (2006), pp. 508-510

10. H. Noureddini, X.J. Gao

Immobilized Pseudomonas cepacia lipase for biodiesel fuel production from soybean oil

Sol-Gel Sci Technol, 41 (2007), pp. 31-41

11. U. Hanefeld, L. Gardossi, E. Magner

Understanding enzyme immobilisation

Chem Soc Rev, 38 (2009), pp. 453-468

12. H. Noureddini, X. Gao, R.S. Philkana

Immobilized Pseudomonas cepacia lipase for biodiesel fuel production from soybean oil Bioresour Technol, 96 (2005), pp. 769-777

13. R.A. Sheldon

Enzyme immobilization: the quest for optimum performance

Adv Synth Catal, 349 (8-9) (2007), pp. 1289-1307

14. C. Garcia-Galan, A. Berenguer-Murcia, R. Fernandez-Lafuente, R.C. Rodrigues

Potential of different enzyme immobilization strategies to improve enzyme performance

Adv Synth Catal, 353 (2011), pp. 2885-2904 
15.

G.F. Bickerstaff

Immbilization of enzymes and cells

Humana Press, Totowa, NJ (1997)

o

16.

L. Cao

Carrier-bound immobilized enzymes: principles, application and design

Wiley-VCH, Wienheim (2005)

17.

C.H. Lee, T.S. Lin, C.Y. Moua

Mesoporous materials for encapsulating enzymes

Nano Today, 4 (2009), pp. 165-179

18. S. Hudson, J. Cooney, E. Magner

Proteins in mesoporous silicates

Angew Chem Int Ed, 47 (2008), pp. 8582-8594

19. J.A. Laszlo, M. Jackson, R.M. Blanco

Active-site titration analysis of surface influences on immobilized Candida antarctica lipase

B activity

J Mol Catal B Enzyme, 69 (2011), pp. 60-65

20. A. Galarneau, M. Mureseanu, S. Atger, G. Renard, F. Fajula

Immobilization of lipase on silicas. Relevance of textural and interfacial properties on activity and selectivity

New J Chem, 30 (4) (2006), pp. 562-571

21. A. Popat, S.B. Hartono, F. Stahr, J. Liu, S.Z. Qiao, G.Q. Lu

Mesoporous silica nanoparticles for bioadsorption, enzyme immobilisation, and delivery carriers

Nanoscale, 3 (7) (2011), pp. 2801-2818

22. T. Orita, M. Tomita, T. Saito, N. Nishida, K. Kato

Immobilization of cholesterol esterase in mesoporous silica materials and its hydrolytic activity toward diethyl phthalate

Mater Sci Eng C, 32 (4) (2012), pp. 718-724

23. C. Wang, G. Zhou, Y. Li, N. Lu, H. Song, L. Zhang

Biocatalytic esterification of caprylic acid with caprylic alcohol by immobilized lipase on amino functionalized mesoporous silica

Colloids Surf Physicochem Eng Asp, 406 (2012), pp. 75-83

24. R.A. Sheldon

Characteristic features and biotechnological applications of cross-linked enzyme aggregates (CLEAs)

Appl Microbiol Biotechnol, 92 (3) (2011), pp. 467-477

25. R.A. Sheldon

Cross-linked enzyme aggregates as industrial biocatalysts

Org Process Res Dev, 15 (1) (2011), pp. 213-223

26. G. Jas, A. Kirchning

Continuous flow techniques in organic synthesis

Chem Eur J, 9 (2003), pp. 5708-5723

27. A. Kirchning, W. Solodenko, K. Mennecke

Combining enabling techniques in organic synthesis: continuous flow processes with heterogenized catalysts 
Chem Eur J, 12 (2006), pp. 5972-5990

28. A. Liese, K. Seelbach, C. Wandrey

Industrial biotransformations

(2nd ed.)Wiley-VCH, Weinheim/New York (2006)

29. C. Csajági, G. Szatzker, E.R. Tőke, L. Ürge, F. Darvas, L. Poppe

Enantiomer selective acylation of racemic alcohols by lipases in continuous-flow bioreactors

Tetrahedron: Asymmetry, 19 (2008), pp. 237-246

30. D. Weiser, Z. Boros, G. Hornyánszky, A. Tóth, L. Poppe

Disubstituted dialkoxysilane precursors in binary and ternary sol-gel systems for lipase immobilization

Process Biochem, 47 (3) (2012), pp. 428-434

31.

G. Hellner, Z. Boros, A. Tomin, L. Poppe

Novel sol-gel lipases by designed bioimprinting for continuous-flow kinetic resolutions

Adv Synth Catal, 353 (13) (2011), pp. 2481-2491

32. A. Tomin, G. Hornyánszky, K. Kupai, Z. Dorkó, L. Ürge, F. Darvas et al.

Lipase-catalyzed kinetic resolution of 2-methylene-substituted cycloalkanols in batch and continuous-flow modes

Process Biochem, 45 (6) (2010), pp. 859-865

33. E.M. Anderson, K.M. Larsson, O. Kirk

One biocatalyst - many applications: the use of Candida antarctica B-lipase in organic synthesis

Biocat Biotrans, 16 (1997), pp. 181-204

34. O. Kirk, M.W. Christensen

Lipases from Candida antarctica: unique biocatalysts from a unique origin

Org Process Res Dev, 6 (2002), pp. 446-451

35. U.T. Bornscheuer, R.J. Kazlauskas

Hydrolases in organic synthesis: regio- and stereoselective biotransformations

(2nd ed.)Wiley-VCH, New York/Weinheim (2006)

36. Z. Boros, P. Falus, M. Márkus, D. Weiser, M. Oláh, G. Hornyánszky et al.

How the mode of Candida antarctica lipase B immobilization effects the continuous-flow kinetic resolution of racemic amines at various temperatures

J Mol Catal B Enzym, 85-86 (2013), pp. 119-125

37. B. Dragoi, E. Dumitriu

Candida antarctica lipase B immobilization onto hybrid organic-inorganic mesoporous materials

Acta Chim Slov, 55 (2008), pp. 277-285

38. R.M. Blanco, P. Terreros, M. Fernández-Pérez, C. Otero, G. Díaz-González

Functionalization of mesoporous silica for lipase immobilization - characterization of the support and the catalysts

J Mol Catal B Enzym, 30 (2004), pp. 83-93

39. P. Lozano, T. De Diego, T. Sauer, M. Vaultier, S. Gmouh, J.L. Iborra

On the importance of the supporting material for activity of immobilized Candida antarctica

lipase B in ionic liquid/hexane and ionic liquid/supercritical carbon dioxide biphasic media J Supercrit Fluids, 40 (1) (2007), pp. 93-100

40. Z. Boros, E. Abaháziová, M. Oláh, P. Sátorhelyi, B. Erdélyi, L. Poppe

Novel hydrophobic silica gels as carriers for lipases-separation of lipase A and lipase B from Candida antarctica

Chim Oggi/Chem Today, 30 (5) (2012), pp. 26-29 
41. M. Arroyo, J.M. Sánchez-Montero, J.V. Sinisterra

Thermal stabilization of immobilized lipase B from Candida antarctica on different supports: effect of water activity on enzymatic activity in organic media

Enzyme Microb Technol, 24 (1-2) (1999), pp. 3-12

42.

A. Ruiz Toral, A.P. de los Ríos, F.J. Hernández, M.H.A. Janssen, R. Schoevaart, F. van Rantwijk et al.

Cross-linked Candida antarctica lipase B is active in denaturing ionic liquids Enzyme Microb Technol, 40 (5) (2007), pp. 1095-1099

0

43. P. Banet, N. Marcotte, D.A. Lerner, D. Brunel

Single-step dispersion of functionalities on a silica surface

Langmuir, 24 (16) (2008), pp. 9030-9037

44. C.S. Chen, Y. Fujimoto, G. Girdaukas, C.J. Sih

Quantitative analyses of biochemical kinetic resolutions of enantiomers

J Am Chem Soc, 104 (1982), pp. 7294-7299

45. P. López-Serrano, L. Cao, F. van Rantwijk, R.A. Sheldon

Cross-linked enzyme aggregates with enhanced activity: application to lipases

Biotechnol Lett, 24 (2002), pp. 1379-1383 
Table 1.

Kinetic resolution of rac-1a with CaLB adsorbed on various surface-functionalized silica supports (reaction time: $4 \mathrm{~h}$ ).

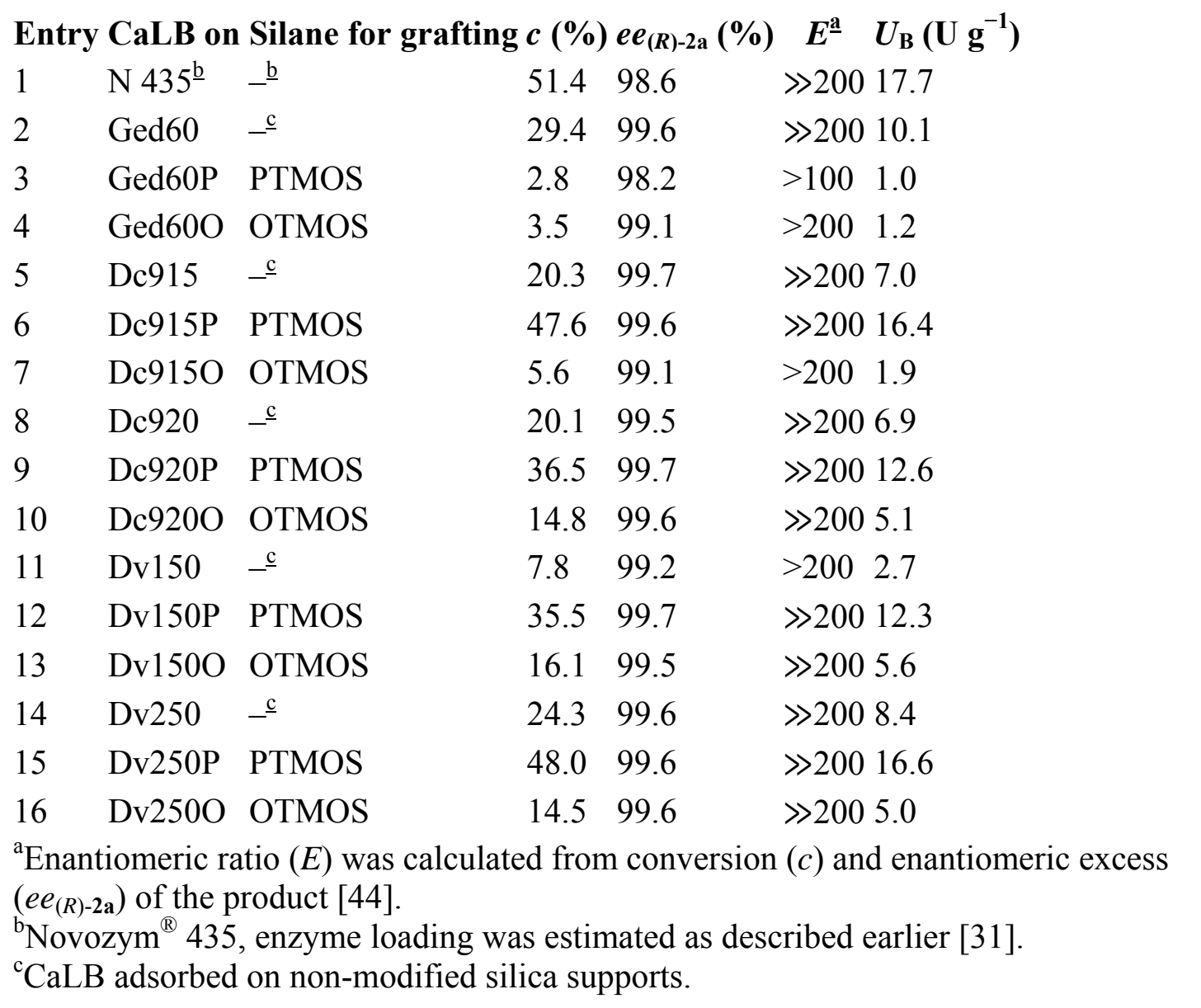




\section{Table 2.}

Kinetic resolution of rac-1a with CaLB immobilized by adsorption (A) or by adsorption and GDA binding/cross-linking (C) onto various aminoalkyl-grafted silica supports (reaction time: $1 \mathrm{~h}$ ).

\begin{tabular}{|c|c|c|c|c|c|c|c|}
\hline Entry & $\begin{array}{c}\text { Silane for Dv250 } \\
\text { grafting }\end{array}$ & $\mathbf{A} / \mathbf{C}^{\mathbf{a}}$ & $\begin{array}{c}\text { CaLB biocatalyst } \\
\text { on Dv250 }\end{array}$ & $\begin{array}{c}c \\
(\%)\end{array}$ & $\begin{array}{c}e e_{(R)-2 a} \\
(\%)\end{array}$ & $E^{\underline{\mathbf{b}}}$ & $\begin{array}{c}U_{B} \\
\left(\mathbf{U ~ g}^{-1}\right)\end{array}$ \\
\hline 1 & - & $\underline{\mathrm{c}}$ & $\mathrm{CLEA}^{\mathrm{c}}$ & 29.5 & 99.9 & $\gg 200$ & 40.7 \\
\hline 2 & APTMOS & A & AP-A & 12.5 & 99.4 & $>200$ & 17.1 \\
\hline 3 & AEAPTMOS & A & AEAP-A & 6.6 & 99.4 & $>200$ & 9.0 \\
\hline 4 & AEAP-MDMOS & A & AEAP-M-A & 6.3 & 99.4 & $>200$ & 8.6 \\
\hline 5 & APTMOS & $\mathrm{C}$ & AP-C & 3.1 & 99.3 & $>200$ & 4.2 \\
\hline 6 & AEAPTMOS & $\mathrm{C}$ & AEAP-C & 1.7 & 99.0 & $>100$ & 2.3 \\
\hline 7 & AEAP-MDMOS & $\mathrm{C}$ & AEAP-M-C & 0.8 & 98.0 & $>100$ & 1.1 \\
\hline
\end{tabular}


Table 3.

Kinetic resolution of rac-1a with CaLB immobilized by adsorption (A) or by adsorption and GDA binding/cross-linking (C) onto various silica supports grafted with mixtures of aminoalkyl- and phenyl-silanes (reaction time: $1 \mathrm{~h}$ ).

\begin{tabular}{|c|c|c|c|c|c|c|c|c|}
\hline Entry & $\begin{array}{c}\text { CaLB } \\
\text { biocatalyst on } \\
\text { Dv250 }\end{array}$ & $\begin{array}{c}\text { Silanes for Dv250 } \\
\text { grafting }\end{array}$ & Ratio & $\mathbf{A} / \mathbf{C}^{\mathrm{a}}$ & $\begin{array}{c}c \\
(\%)\end{array}$ & $\begin{array}{c}e e_{(R)-} \\
2 \mathrm{a} \\
(\%)\end{array}$ & $\boldsymbol{E}^{\mathbf{b}}$ & $\begin{array}{c}U_{\mathrm{B}} \\
\left(\mathbf{U}^{-1}\right)\end{array}$ \\
\hline 1 & PAP13-A & PTMOS:APTMOS & $1: 3$ & A & 41.4 & 99.7 & $\gg 200$ & 57.0 \\
\hline 2 & PAP11-A & PTMOS:APTMOS & $1: 1$ & $\mathrm{~A}$ & 43.5 & 99.8 & $\gg 200$ & 59.9 \\
\hline 3 & PAP31-A & PTMOS:APTMOS & $3: 1$ & A & 43.9 & 99.7 & $\gg 200$ & 60.5 \\
\hline 4 & PAEAP13-A & PTMOS:AEAPTMOS & $1: 3$ & $\mathrm{~A}$ & 37.5 & 99.8 & $\gg 200$ & 51.7 \\
\hline 5 & PAEAP11-A & PTMOS:AEAPTMOS & $1: 1$ & $\mathrm{~A}$ & 46.8 & 99.7 & $\gg 200$ & 64.5 \\
\hline 6 & PAEAP31-A & PTMOS:AEAPTMOS & $3: 1$ & $\mathrm{~A}$ & 43.1 & 99.7 & $\gg 200$ & 59.4 \\
\hline 7 & PAEAPM13-A & $\begin{array}{l}\text { PTMOS:AEAP- } \\
\text { MDMOS }\end{array}$ & $1: 3$ & A & 44.9 & 99.8 & $\gg 200$ & 61.9 \\
\hline 8 & PAEAPM11-A & $\begin{array}{l}\text { PTMOS:AEAP- } \\
\text { MDMOS }\end{array}$ & $1: 1$ & A & 45.2 & 99.8 & $\gg 200$ & 62.3 \\
\hline 9 & PAEAPM31-A & $\begin{array}{l}\text { PTMOS:AEAP- } \\
\text { MDMOS }\end{array}$ & $3: 1$ & $\mathrm{~A}$ & 45.8 & 99.7 & $\gg 200$ & 63.1 \\
\hline 10 & PAP13-C & PTMOS:APTMOS & $1: 3$ & $\mathrm{C}$ & 11.9 & 98.8 & $>100$ & 16.4 \\
\hline 11 & PAP11-C & PTMOS:APTMOS & $1: 1$ & $\mathrm{C}$ & 21.7 & 98.8 & $>200$ & 29.9 \\
\hline 12 & PAP31-C & PTMOS:APTMOS & $3: 1$ & $\mathrm{C}$ & 32.0 & 99.0 & $>200$ & 44.0 \\
\hline 13 & PAEAP13-C & PTMOS:AEAPTMOS & $1: 3$ & $\mathrm{C}$ & 10.3 & 99.1 & $>200$ & 14.2 \\
\hline 14 & PAEAP11-C & PTMOS:AEAPTMOS & $1: 1$ & $\mathrm{C}$ & 24.9 & 99.0 & $>200$ & 34.4 \\
\hline 15 & PAEAP31-C & PTMOS:AEAPTMOS & $3: 1$ & $\mathrm{C}$ & 23.7 & 99.2 & $>200$ & 32.6 \\
\hline 16 & PAEAPM13-C & $\begin{array}{l}\text { PTMOS:AEAP- } \\
\text { MDMOS }\end{array}$ & $1: 3$ & $\mathrm{C}$ & 18.6 & 99.5 & $>200$ & 25.6 \\
\hline 17 & PAEAPM11-C & $\begin{array}{l}\text { PTMOS:AEAP- } \\
\text { MDMOS }\end{array}$ & $1: 1$ & $\mathrm{C}$ & 26.5 & 99.2 & $>200$ & 36.6 \\
\hline 18 & PAEAPM31-C & $\begin{array}{l}\text { PTMOS:AEAP- } \\
\text { MDMOS }\end{array}$ & $3: 1$ & $\mathrm{C}$ & 26.1 & 99.2 & $>200$ & 36.0 \\
\hline
\end{tabular}


Fig. 1.

Scanning electron microscopy (SEM) analysis of immobilized CaLB biocatalysts at low $(150 \times)$ and medium (1000-3000×) magnification.
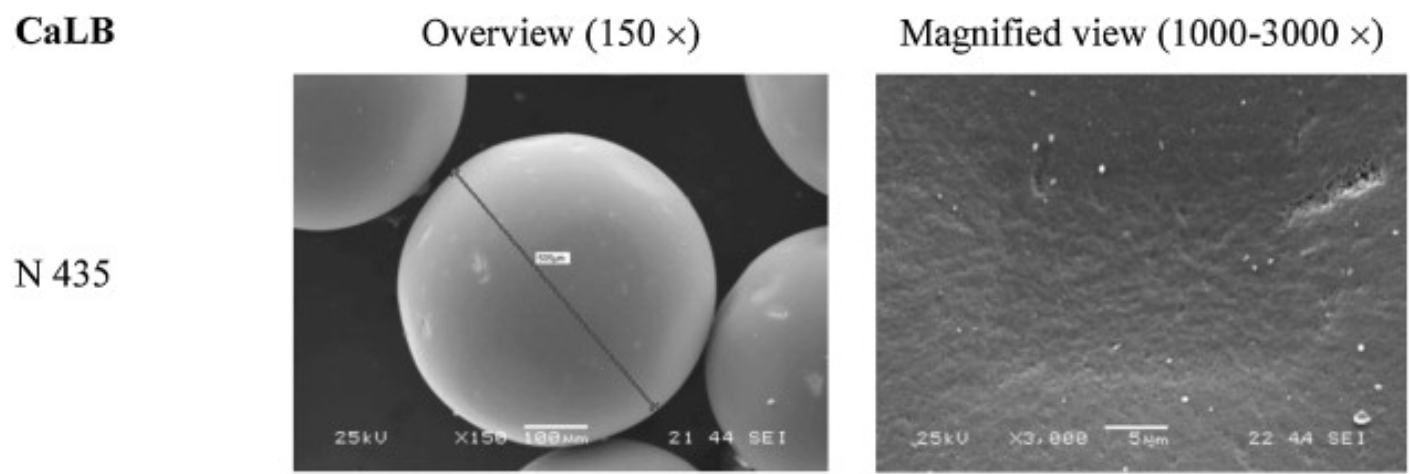

$\mathrm{T} 2-150$
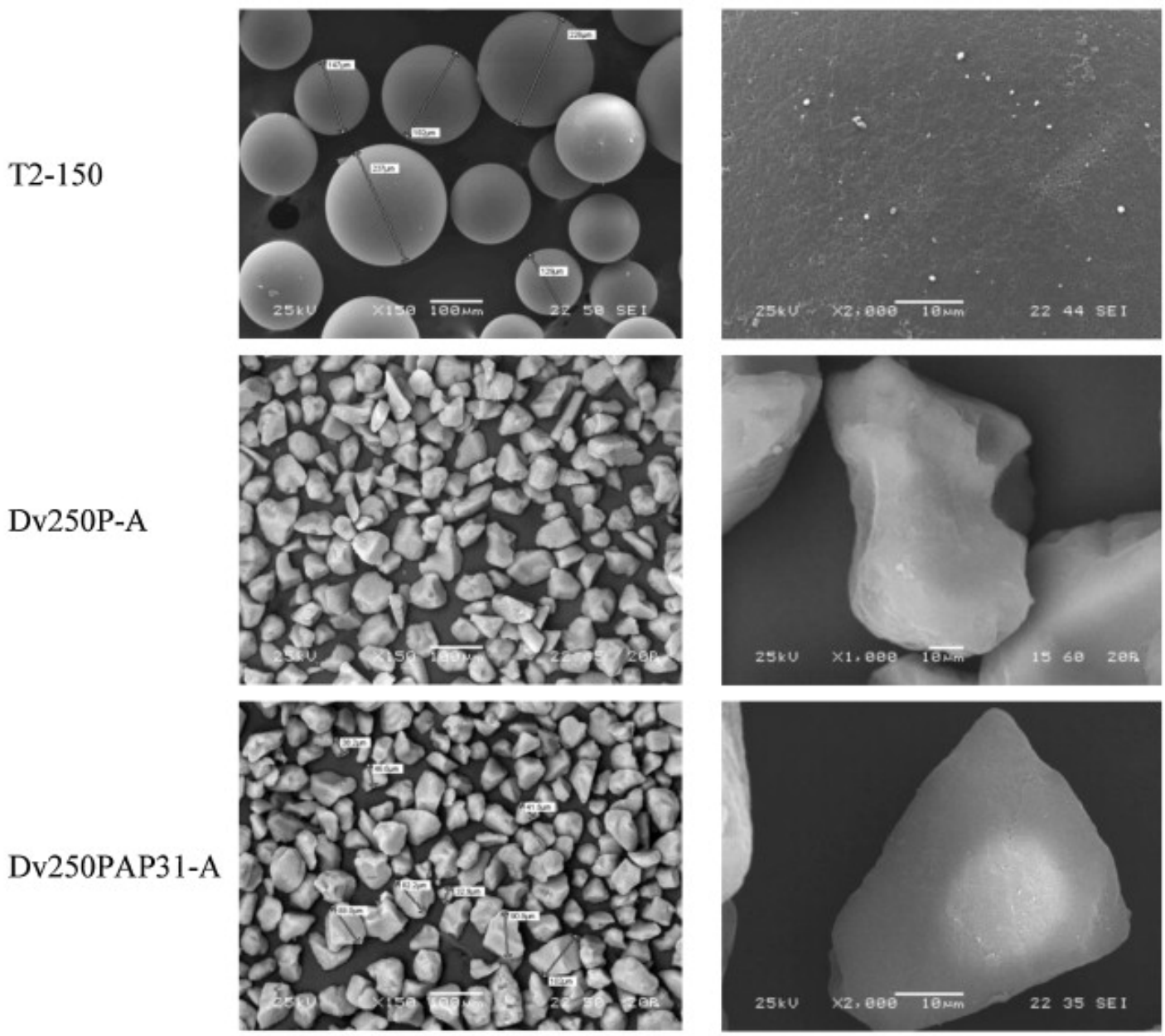

Dv250PAP31-C
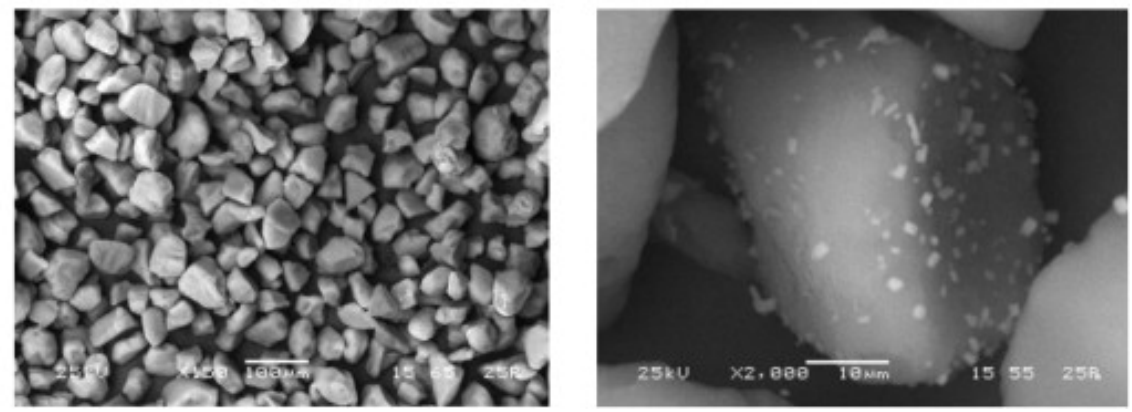
Fig. 2.

Enzyme desorption tests of immobilized CaLB biocatalysts with phosphate buffer $(10 \mathrm{mM}, \mathrm{pH} 7.5)$ and Triton $\mathrm{X}-100$ solution $(2 \%, \mathrm{v} / \mathrm{v})$.

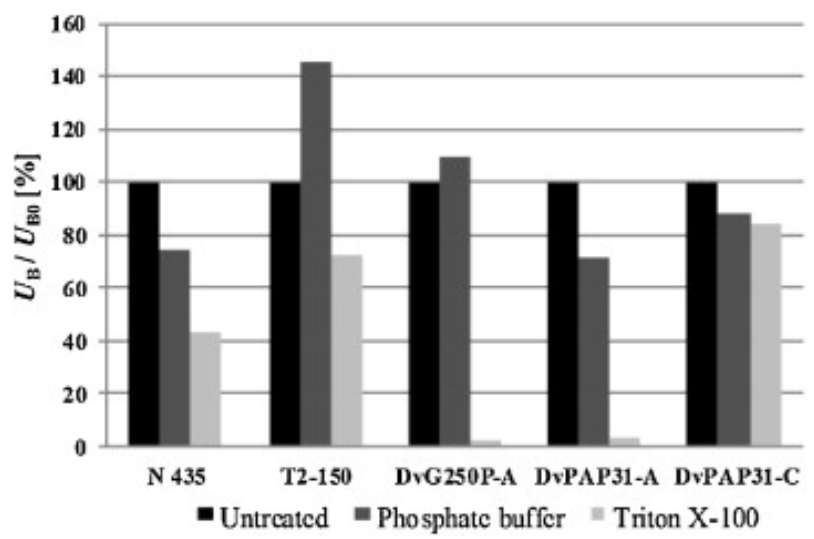

Fig. 3.

Continuous-flow kinetic resolution of racemic 1-phenylethanol rac-1a and racemic 1phenylethanamine rac-1b catalyzed by variously immobilized forms of lipase B from Candida antarctica.

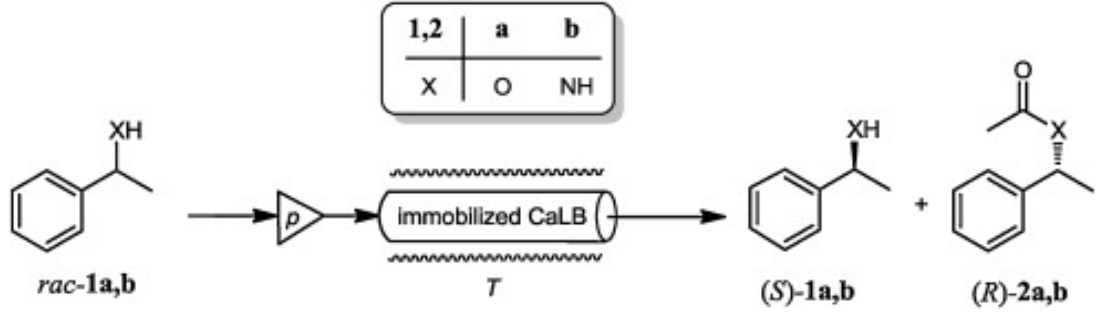


Fig. 4.

Temperature-dependent biocatalytic properties $\left(r_{\text {flow }}, E\right.$ and $\left.e e_{(R)-2 a}\right)$ of variously immobilized CaLB biocatalysts during the kinetic resolution of racemic 1phenylethanol (rac-1a) by acylation with vinyl acetate in continuous-flow reactors.
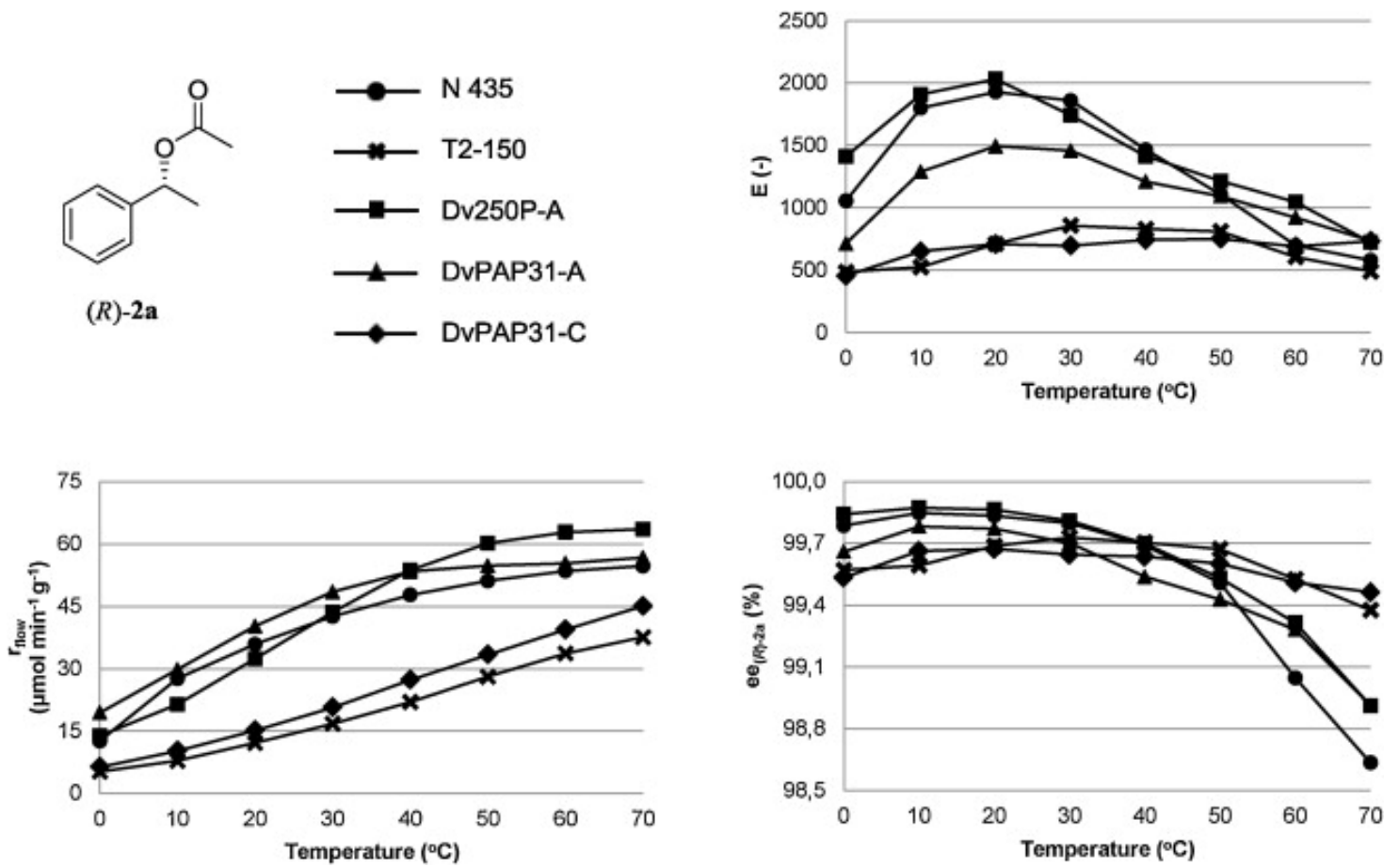


\section{Fig. 5.}

Temperature-dependent biocatalytic properties $\left(r_{\text {flow }}, E\right.$ and $\left.e e_{(R)-2 \mathbf{b}}\right)$ of variously immobilized CaLB biocatalysts during the kinetic resolution of racemic 1phenylethanamine $(r a c-1 b)$ by acylation with ethyl acetate in continuous-flow reactors.
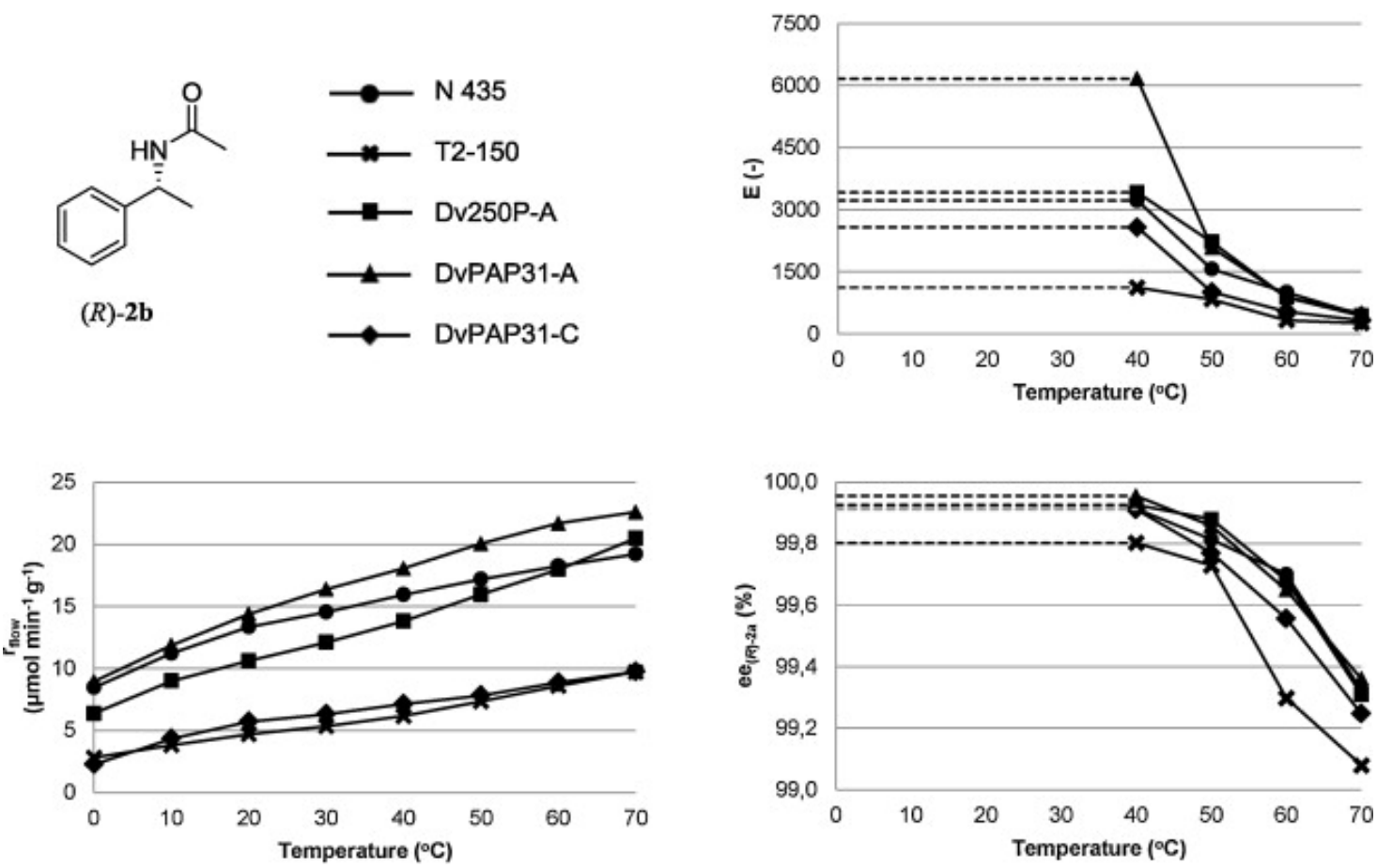